\title{
Structural and optical properties of $\mathrm{Zn}_{1-\mathrm{x}} \mathrm{Co}_{\mathrm{x}} \mathrm{O}$ thin films prepared by $R F$ reactive sputtering technique
}

\author{
A.I. Savchuk ${ }^{1}$, I.D. Stolyarchuk ${ }^{1}$, I. Stefaniuk ${ }^{2}$, B. Cieniek $^{2}$, E. Sheregii ${ }^{2}$ \\ ${ }^{I}$ Chernivtsi National University, Department of Physics of Semiconductors and Nanostructures, \\ 2, Kotsyubynskystr., 58012 Chernivtsi,Ukraine, e-mail: istolyarchuk@ukr.net \\ ${ }^{2}$ Centre for Innovation and Transfer of Natural Sciences and Engineering Knowledge, \\ University of Rzeszow, 16 a Rejtana str., 35959 Rzeszow, Poland
}

\begin{abstract}
We have reported the effect of Co doping on structural and optical properties of $\mathrm{ZnO}$ thin films prepared by the RF reactive sputtering technique. The composite targets were formed by mixing and pressing $\mathrm{ZnO}$ and $\mathrm{CoO}$ powders. The thin films were deposited on silica and glass substrates. The structures of samples have been studied by using X-ray diffraction (XRD) and atomic force microscopy (AFM). With the sensitivity of the XRD instruments, the structural analyses of Co-doped $\mathrm{ZnO}$ films reveal formation of predominant (002) reflection corresponding to the hexagonal wurtzite structure without any secondary phase. The AFM study showed that surface morphology of the $\mathrm{Zn}_{1-\mathrm{x}} \mathrm{Co}_{\mathrm{x}} \mathrm{O}$ films is composed of closely packed nanocrystallites with nanorod shape. The optical properties of the samples were studied using UV-vis absorption and PL spectra. The optical absorption spectra show a red shift of the band edge, which indicates that $\mathrm{Co}^{2+}$ ions substitute $\mathrm{Zn}^{2+}$ ions in $\mathrm{ZnO}$ lattice. In the room-temperature photoluminescence spectra, four main peaks were revealed in all the samples, which are attributed to ultraviolet, violet-blue, blue and green emission.
\end{abstract}

Keywords: $\mathrm{ZnCoO}$, thin films, RF sputtering, X-ray diffraction, optical absorption, photoluminescence.

Manuscript received 19.02.14; revised version received 30.07.14; accepted for publication 29.10.14; published online 10.11.14.

\section{Introduction}

Diluted magnetic semiconductors (DMS) are semiconducting materials doped with magnetic transition metal (TM) (such as $\mathrm{Mn}, \mathrm{Fe}, \mathrm{Co}, \mathrm{Ni}$ etc.) ions have attracted much interest in recent years because of their potential application in optoelectronic, magnetoelectronic and spintronic devices [1-3]. These are basic semiconductors where the cation sites of the host lattice are replaced by transition metal atoms. Recently the family of DMS has been increased by addition of the semiconducting oxides $[4,5]$.

Zinc oxide $(\mathrm{ZnO})$, an optically transparent II-VI semiconductor with hexagonal wurtzite structure of $C_{6 v}^{4} \quad\left(P 6_{3 m c}\right)$ space group, wide direct band gap $\left(E_{g} \sim\right.$ $3.37 \mathrm{eV})$, exciton binding energy $(\sim 60 \mathrm{meV})$ has been identified as a promising host material after theoretical studies that predicted ferromagnetism above room temperature in Mn-doped $\mathrm{ZnO}$ [6]. Among those transition metals, cobalt is an important dopant that has been intensively investigated. Different growth techniques such as chemical vapor deposition, spray pyrolysis, pulsed laser deposition, magnetron sputtering, sol-gel process etc. have been used for preparing Co-doped $\mathrm{ZnO}$ thin films. The magnetic property of $\mathrm{ZnCoO}$ thin films has been the focus of numerous investigations. Several groups $[7,8]$ have observed ferromagnetism in $\mathrm{ZnO}$ :Co systems, while in other groups $[9,10]$ this magnetic behavior is not observed in similar samples. These controversial results indicated that the magnetic properties are very sensitive to the shape of the samples and to the preparation conditions. 
The present work is devoted to preparation of $\mathrm{ZnCoO}$ thin films and study of their structural, absorption and photoluminescence properties depending on the content of cobalt.

\section{Experimental}

$\mathrm{Zn}_{1-\mathrm{x}} \mathrm{Co}_{\mathrm{x}} \mathrm{O}$ (where $x=0.02,0.04,0.06$ ) thin films were deposited onto glass and silica substrates using the RF reactive sputtering technique. The composite targets were formed by mixing and pressing $\mathrm{ZnO}$ and $\mathrm{CoO}$ powders with appropriate ratios of components. The sputtering was performed under a mixture of argon and oxygen atmosphere that served as operation and reactive gases, respectively, through independent mass flow controllers. The sputtering chamber was evacuated down to $2 \cdot 10^{-4} \mathrm{~Pa}$ before $\mathrm{Ar}$ and $\mathrm{O}_{2}$ gases were filled with the flow ratio $4: 1$. During the sputtering, the RF power, deposition rate, substrate-to-target distance and substrate temperature were kept at $300 \mathrm{~W}, 10 \mathrm{~nm} / \mathrm{min}, 35 \mathrm{~mm}$ and $350 \ldots 400{ }^{\circ} \mathrm{C}$, respectively. Postdeposition annealing $5 \ldots 8 \mathrm{~min}$ in oxygen atmosphere at $500 \ldots 550{ }^{\circ} \mathrm{C}$ was performed.

The crystallographic studies were performed using X-ray Diffractometer (D8 ADVANCE X-ray Diffractometer with DAVINCI) using $\mathrm{CuK}_{\alpha}$ wavelength $(\lambda=$ $1.54059 \AA$ ) and scanning in $2 \Theta$ range from $10^{\circ}$ to $70^{\circ}$.

The surface analysis was performed using atomic force microscopy (AFM) "Nanotec Electronica" in Dynamic Mode (non-contact) with the force constant $K \sim 40 \mathrm{~N} / \mathrm{m}$ and $f_{0} \sim 300 \mathrm{kHz}$. Optical transmission and absorption spectra between 300 and $700 \mathrm{~nm}$ were measured using a grating monochromator, photodetector system and registering computer system. This setup was also used to register photoluminescence spectra. For this kind of measurements, the samples were excited using a 325-nm He-Cd laser with the excitation intensity $10 \mathrm{~mW}$.

\section{Results and discussion}

The X-ray diffraction (XRD) patterns of $\mathrm{Zn}_{1-\mathrm{x}} \mathrm{Co}_{\mathrm{x}} \mathrm{O}$ $(0 \leq x \leq 0.06)$ films are shown in Fig. 1 . All intense peak positions of the films correspond to the standard diffraction pattern of $\mathrm{ZnO}$ hexagonal wurtzite with a (002) preferred orientation. With an increase in Co content $(x>0.02)$ additional diffraction peaks were observed, corresponding to (100), (101), and (102) of $\mathrm{ZnO}$. No peaks corresponding to cobalt metal clusters or cobalt oxides were observed on the patterns, which indicates that $\mathrm{Co}$ enters the $\mathrm{ZnO}$ lattice without changing the wurtzite structures and systematically substitutes $\mathrm{Zn}^{2+}$ ions in the lattice. The relative intensity of the $(002)$ peak of $\mathrm{Zn}_{1-\mathrm{x}} \mathrm{Co}_{\mathrm{x}} \mathrm{O}(0 \leq x \leq 0.06)$ reaches higher values than that of other peaks, indicating the $c$-axis preferred texture growth of the Co-doped $\mathrm{ZnO}$ films. Further, the intensity of diffraction peaks of $\mathrm{Zn}_{1-\mathrm{x}} \mathrm{Co}_{\mathrm{x}} \mathrm{O}$ films increased with increasing Co concentration, which can be attributed to a refinement and improvement of crystalline quality of these films as a result of Co doping. At the same time, we observed a shift only in the angular peak position of (002) plane, and no angular shift was observed for any other plane. This angular peak shift towards the lower $2 \Theta$ value, when transfering from the undoped sample to the doped up to $x=0.04$ one, indicates that films are in a uniform state of stress. With a further increase in the Co concentration, the peak shift takes place in opposite direction, i.e. $2 \Theta$ value increases, indicating the change in the direction of stress. The average crystallite size $D$ was calculated using the full width at the half maximum (FWHM) of the diffraction peak and the angle of diffraction $\Theta$ in DebyeScherer's formula [11]:

$D=\frac{0.9 \lambda}{\Delta \Theta \cos \Theta}$,

where $\lambda$ is the X-ray wavelength, $\Delta \Theta-$ FWHM, and $\Theta-$ Bragg angle of the diffraction peak. The lattice parameters $a$ and $c$ for the samples were calculated using the appropriate formula and depicted in Fig. 2. Codoping slightly decreases the lattice parameters of the $\mathrm{ZnO}$ films, considering that the size of $\mathrm{Co}^{2+}$ in tetrahedral configuration $(0.058 \mathrm{~nm})$ is close to that of $\mathrm{Zn}^{2+}$ in tetrahedral coordination $(0.06 \mathrm{~nm})$. Thus, the $\mathrm{Co}^{2+}$ ions are systematically substituted by $\mathrm{Zn}^{2+}$ ions without changing the crystal structure.

The surface morphology of the $\mathrm{Zn}_{1-\mathrm{x}} \mathrm{Co}_{\mathrm{x}} \mathrm{O}$ films and their crystallite sizes have been studied and evaluated by AFM. The root mean square of the surface roughness is measured from the pictures over $5 \times 5 \mu \mathrm{m}$ scanning range. The AFM micrograph shown in Fig. 3 indicates that the increase in the surface roughness after Co doping is caused by closely packed nanorod-like nanocrystallites oriented non-perpendicularly to the film-substrate plane over the whole $\mathrm{Zn}_{0.98} \mathrm{Co}_{0.02} \mathrm{O}$ film surface. The estimated diameter of the observed nanorods is about $100 \mathrm{~nm}$. Essentially, there is no obvious change in the microstructure observed in the films grown with different Co concentrations.

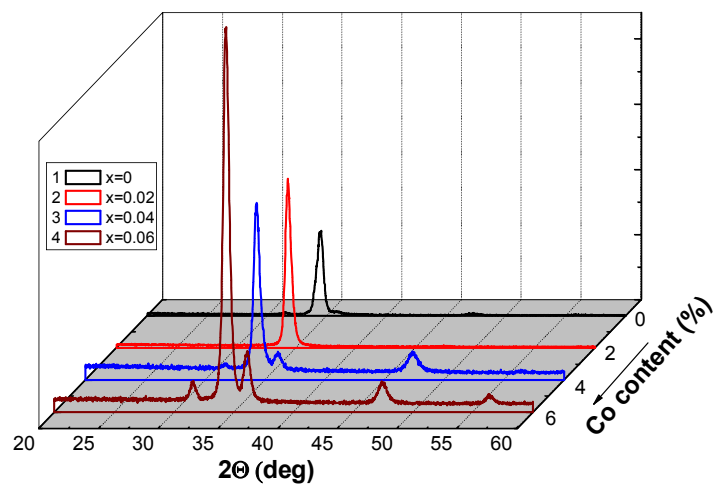

Fig. 1. X-ray diffraction spectra of $\mathrm{Co}$ doped $\mathrm{ZnO}$ thin films with various doping levels. 


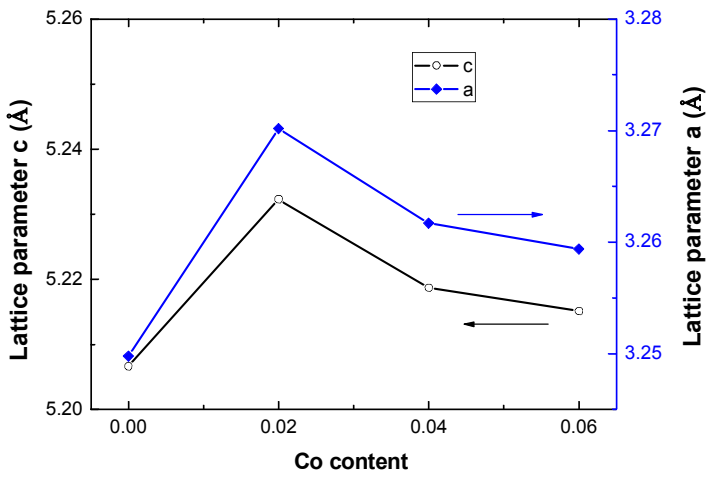

Fig. 2. Variation of lattice parameters $a$ and $c$ with increasing the Co content in $\mathrm{Zn}_{1-\mathrm{x}} \mathrm{Co}_{\mathrm{x}} \mathrm{O}$ thin films.

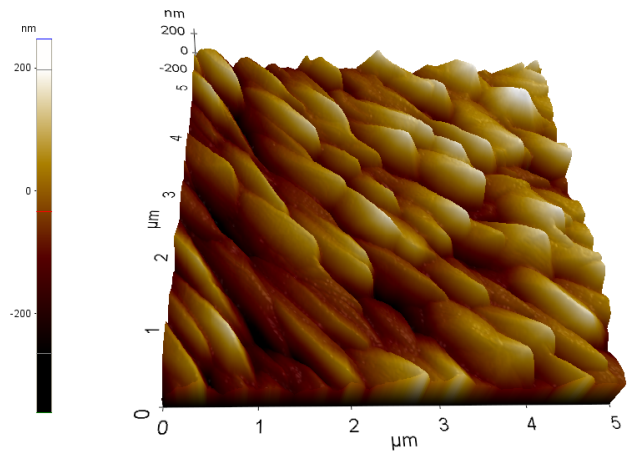

Fig. 3. 3D AFM images of $\mathrm{Zn}_{1-\mathrm{x}} \mathrm{Co}_{\mathrm{x}} \mathrm{O}$ thin films with the $\mathrm{Co}$ content $x=0.02$.

UV-vis optical measurements were carried out at room temperature to study the effect of Co doping concentration on the band gap of $\mathrm{ZnO}$ thin films and to confirm the substitution of $\mathrm{Co}^{2+}$ ions in tetrahedral sites of the $\mathrm{ZnO}$ wurtzite structures. Fig. 4 shows the optical transmission spectra of undoped and cobalt doped $\mathrm{ZnO}$ thin films deposited on glass substrates. The undoped $\mathrm{ZnO}$ film is more transparent, whereas in cobalt-doped thin films the transmittance decreases with the increase of Co-doping concentration. The optical transmittance spectra showed a shift in the band edge towards the lower energy side with the increase of Co content in the films. Additional absorption below the absorption edge can be seen for the $\mathrm{Zn}_{1-\mathrm{x}} \mathrm{Co}_{\mathrm{x}} \mathrm{O}$ thin films. In particular, for the Co content $x=0.02$, three absorption bands at about $1.87,2.03$ and $2.19 \mathrm{eV}$ have been revealed, which are in agreement with already reported absorption peaks $[12,13]$. This absorption structure is associated with $d-d$ electron transitions of $\mathrm{Co}^{2+}$ ions in a tetragonal crystal field. According to Hund's rule and Pauli's exclusion principle, the electronic ground state configuration has $\mathrm{L}=3$ and $\mathrm{S}=3 / 2$. So, the ground state spectral term is ${ }^{4} \mathrm{~F}$ and the excited state terms are ${ }^{4} \mathrm{P},{ }^{2} \mathrm{G},{ }^{2} \mathrm{~F},{ }^{2} \mathrm{D}$ and ${ }^{2} \mathrm{P}$. However, when $\mathrm{Co}^{2+}$ exists in the tetrahedral field, the ${ }^{4} \mathrm{~F}$ term splits into ${ }^{4} \mathrm{~A}_{2}(\mathrm{~F}),{ }^{4} \mathrm{~T}_{2}(\mathrm{~F})$ and ${ }^{4} \mathrm{~T}_{1}(\mathrm{~F})$, with ${ }^{4} \mathrm{~A}_{2}(\mathrm{~F})$ being the lowest in energy and the remaining two having higher energies. The ${ }^{4} \mathrm{P}$ term corresponding to the first excited state does not split, but is transformed into ${ }^{4} \mathrm{~T}_{1}(\mathrm{P})$. Similarly, ${ }^{2} \mathrm{G}$ splits into ${ }^{2} \mathrm{~A}_{1}(\mathrm{G}),{ }^{2} \mathrm{E}(\mathrm{G}),{ }^{2} \mathrm{~T}_{1}(\mathrm{G})$ and ${ }^{2} T_{2}(G)$. In the ground state, the atom is in ${ }^{4} A_{2}$ state. When electron has a sufficient energy, it can be excited to a higher energy state. The observed peaks were attributed to ${ }^{4} \mathrm{~A}_{1}(\mathrm{~F}) \rightarrow{ }^{2} \mathrm{~A}_{1}(\mathrm{G}),{ }^{4} \mathrm{~A}_{2}(\mathrm{~F}) \rightarrow{ }^{4} \mathrm{~T}_{1}(\mathrm{P})$ and ${ }^{4} \mathrm{~A}_{2}(\mathrm{~F}) \rightarrow{ }^{2} \mathrm{E}(\mathrm{G})$ transitions in $\mathrm{Co}^{2+}$ ions. Thus, observation of these transitions in transmission spectra of our $\mathrm{Zn}_{1-\mathrm{x}} \mathrm{Co}_{\mathrm{x}} \mathrm{O}$ films clearly reveals that the added cobalt atoms have been substituted by $\mathrm{Zn}^{2+}$ cations and are present in $2+$ state.

The optical band-gap energy $\left(E_{g}\right)$ values for these films were evaluated by plotting $(\alpha h v)^{2}$ versus $h v$, where $h v$ is the photon energy, and $\alpha$ is the absorption coefficient that can be calculated from the film thickness $d$ as well as transmittances $T$ and $T_{0}$, for the film and substrate, respectively, using equation $\alpha=$ $-(1 / d) \ln \left(T / T_{0}\right)$. Extrapolation of the linear portion of $(\alpha h v)^{2}$ to zero gives the value of $E_{g}$. The estimated $E_{g}$ values are decreased with increase of the Co content (Fig. 5). This result is in contrast with the reported data $[13,15]$ where a blue shift of the absorption edge was observed. On the other side, a similar trend of decrease of the band edge in $\mathrm{Zn}_{1-\mathrm{x}} \mathrm{Co}_{\mathrm{x}} \mathrm{O}$ films is reported by many researchers $[12,14,16]$. This low-energy shift of $E_{g}$ as a function of the Co content can be explained by two reasons: (i) it might result from destabilization of $\mathrm{O}^{2-}\left(2 \mathrm{p}^{6}\right.$ orbitals at $\mathrm{O}^{2-}$ ions adjacent to $\left.\mathrm{Co}^{2+}\right)$, which extends the valence band edge by $0.5 \mathrm{eV}$ [17] or point defects such as nanoclusters of $\mathrm{Co}, \mathrm{CoO}$ can also lead to this shift [18] (however, these defects have not been observed in the present films); (ii) as mainly due to the $s$ - $d$ and $p$ - $d$ spin-exchange interactions between band electrons and localized $d$-electrons of $\mathrm{Co}^{2+}$ ions substituting $\mathrm{Zn}^{2+}$ ions [7, 19]. The exchange interaction between transition metal ions and band electrons gives rise to negative and positive corrections to the conduction and valence-band edges, leading to narrowing the band gap [20].

Room temperature photoluminescence (PL) of $\mathrm{Zn}_{1-\mathrm{x}} \mathrm{Co}_{\mathrm{x}} \mathrm{O}$ thin films measured by exciting at $325 \mathrm{~nm}$ is shown in Fig. 6. The PL spectra show four peaks occurring around 386, 426, 443, and $538 \mathrm{~nm}$ for all the samples on glass and silica substrates. The first peak is in the ultraviolet region, while other three peaks correspond to the violet-blue, blue and green ones, respectively, i.e., in the visible region. The UV emission band is frequently observed in $\mathrm{ZnO}$ film and can be attributed to the near-band-edge exciton emission, because the emission energy is almost equal to the band energy of $\mathrm{ZnO}$ [21] estimated by UV-vis measurements. With a Co doping content increase, the UV emission center shifts to long wavelengths. It can be attributed to the strong exchange interactions between $d$-electrons of doping ion and $s-, p$-electrons of the host band [22]. This red shift of near-band-edge emission confirms that the band gap of $\mathrm{Zn}_{1-\mathrm{x}} \mathrm{Co}_{\mathrm{x}} \mathrm{O}$ decreases with increasing the $\mathrm{Co}$ content and is in good agreement with data obtained 
from optical absorption studies. The violet-blue emission centered near $426 \mathrm{~nm}$ is probably due to radiative defects related to traps existing at grain boundaries and emitted due to the radiative transition between this level and the valence band [23, 24].

With increasing the Co concentration, the peak position of blue emission shifts slightly to higher wavelengths from 443 up to $448 \mathrm{~nm}$. The mechanism of blue emission $(\sim 443 \mathrm{~nm})$ in $\mathrm{ZnO}$ low-dimensional

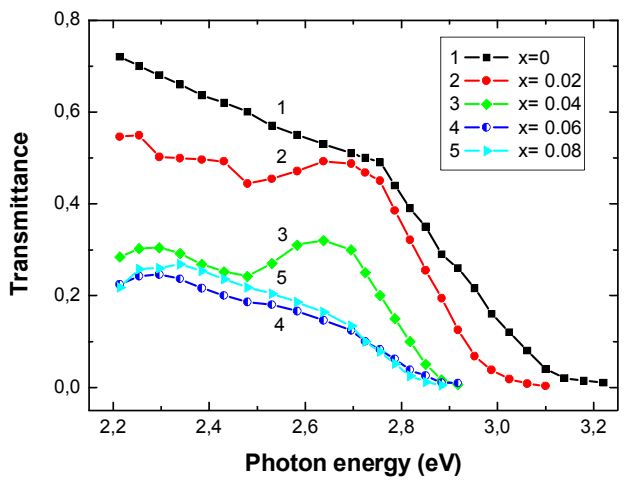

Fig. 4. Transmittance spectra of $\mathrm{Zn}_{1-\mathrm{x}} \mathrm{Co}_{\mathrm{x}} \mathrm{O}$ thin films with various contents of $\mathrm{Co}$ in the spectral region near the absorption edge.

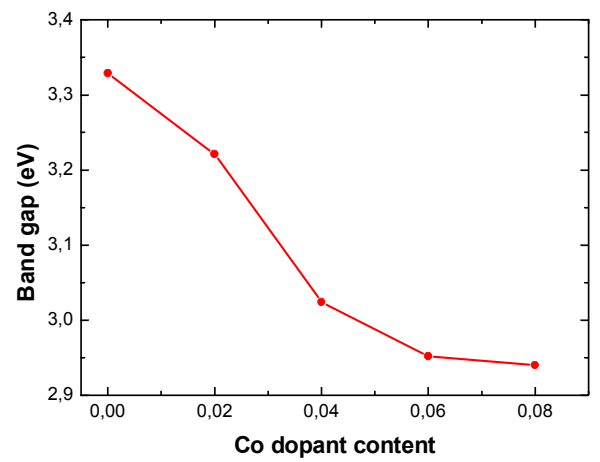

Fig. 5. The energy band gap of $\mathrm{Zn}_{1-\mathrm{x}} \mathrm{Co}_{\mathrm{x}} \mathrm{O}$ thin films as a function of the Co content.

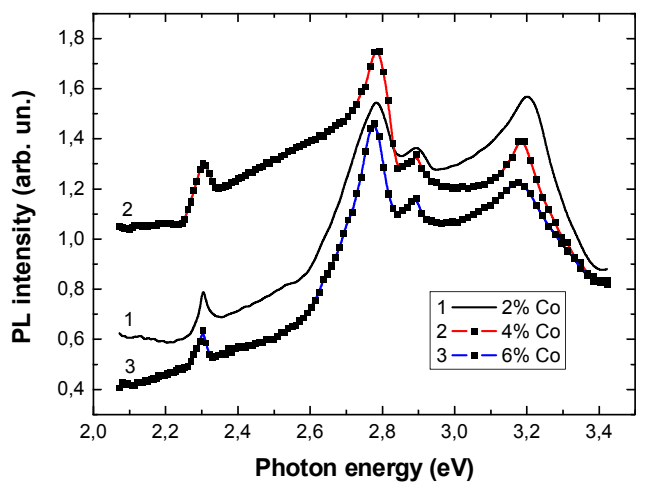

Fig. 6. The room temperature PL spectra of $\mathrm{Zn}_{1-x} \mathrm{Co}_{x} \mathrm{O}$ thin films with various Co contents. structures is still controversial. Xu et al. [25] synthesized single crystalline $\mathrm{ZnO}$ nanoplates by hydrothermal procedure and attributed blue emission to electron transitions from the level of ionized oxygen vacancies to the valence band. Gokulakrishnan et al. [26] studied Zrdoped $\mathrm{ZnO}$ thin films and ascribed the 443-nm centered emission band to a surface defect in the $\mathrm{ZnO}$ films. R. Elilarassi, G. Chandrasekaran [27] and Zeng et al. [28] attributed this peak to the interstitial $\mathrm{Zn}$ level $\left(\mathrm{Zn}_{i}\right)$ and valence band. F.L. Xian et al. [29] attributed the blue emission to the states of interstitial cobalt transition to the valence band. In the latter, it indicates the red shift and change in intensity of emission band with increase of the Co content. The green band emission centered at approximately $538 \mathrm{~nm}$ is related to oxygen vacancy, and it is assigned to transitions from single ionized oxygen vacancies $\left(\mathrm{V}_{\mathrm{O}}\right)$ to the valence band $[30,31]$.

\section{Conclusions}

In conclusion, $\mathrm{Zn}_{1-\mathrm{x}} \mathrm{Co}_{\mathrm{x}} \mathrm{O}$ thin films with $x \leq 0.06$ were deposited by the RF reactive sputtering technique on glass and silica substrates. XRD analysis of the films reveals that cobalt ions are successfully doped in $\mathrm{ZnO}$ without changing the hexagonal wurtzite structure. The grown Co-doped $\mathrm{ZnO}$ films show $c$-axis preferred orientation with good crystallinity. AFM study shows that the surface morphology of the $\mathrm{Zn}_{1-\mathrm{x}} \mathrm{Co}_{\mathrm{x}} \mathrm{O}$ films is composed of closely packed nanocrystallites with nanorod shape. The optical absorption spectra of the films demonstrate that the energy band gap was found to decrease with the Co content increase. Band gap narrowing effect occurs due to strong exchange interactions between $d$-electrons of doping ion and $s-, p$ electrons of the host lattice. The room temperature PL measurements illustrate that UV emission and violetblue, blue and green emissions are in the visible region. The UV emission peak originates from the radiative recombination of free excitons and their center shifts to long wavelengths with increasing the Co content. Other emissions may be attributed to the radiative defects related to traps existing at grain boundaries for violetblue emission, cobalt and zinc interstitial for blue emission, and singly ionized oxygen vacancies $\left(\mathrm{V}_{\mathrm{O}}\right)$ for green band emission, respectively.

\section{References}

1. U. Ozgur, Ya.I. Alivov, C. Liu, A. Teke, M.A. Reshchikov, S. Dogan, V. Avrutin, S.J. Cho, and $\mathrm{H}$. Morkoc, A comprehensive review of $\mathrm{ZnO}$ materials and devices // J. Appl. Phys. 98, 041301103 (2005).

2. D.D. Awschalom, D. Loss, N. Samarth (Eds.), Semiconductor Spintronics and Quantum Computation. Springer, Berlin, 2002.

3. Y. Ohno, D.K. Young, B. Beschoten, F. Matsukura, H. Ohno, and D.D. Awschalom, Electrical spin 
injection in a ferromagnetic semiconductor heterostructure // Nature, 402, p. 790-792 (1999).

4. S.J. Pearton, W.H. Heo, M. Ivill, D.P. Norton, T. Steiner, Dilute magnetic semiconducting oxides // Semicond. Sci. Technol. 19, p. R59-R74 (2004).

5. S.J. Pearton, D.P. Norton, K. Ip, Y.W. Heo, T. Steiner, Recent progress in processing and properties of $\mathrm{ZnO} / /$ Progr. Mater. Sci. 50, p. 293 340 (2005).

6. T. Dietl, H. Ohno, F. Matsukura, J. Cibert, D. Ferrand, Zener model description of ferromagnetism in zinc-blende magnetic semiconductors // Science, 287, p. 1019-1022 (2000).

7. X. Xu, C. Cao, Hydrothermal synthesis of Co-doped $\mathrm{ZnO}$ flakes with room temperature ferromagnetism // J. Alloys Compound. 501, p. 265-268 (2010).

8. K.P. Bhatti, V.K. Malik, S. Chaudhary, Cobalt substituted $\mathrm{ZnO}$ thin films: a potential candidate for spintronics // J. Mater Sci.: Mater. Electron. 19, p. 849-854 (2008).

9. Y. Belghazi, M. Ait Aouaj, M. El Yadari, G. Schmerber, C. Ulhaq-Bouillet, C. Leuvrey, S. Colis, M. Abd-lefdil, A. Berrada, A. Dinia, Elaboration and characterization of Co-doped $\mathrm{ZnO}$ thin films deposited by spray pyrolysis technique // Microelectronics J. 40, p. 265-267 (2009).

10. A.S. Risbud, N.A. Spaldin, Z.Q. Chen, S. Stemmer, and R. Seshadri, Magnetism in polycrystalline cobalt-substituted zinc oxide // Phys. Rev. B, 68, 205202 (2003).

11. B.D. Cullity, Elements of X-ray Diffractions. Addison-Wesley, Reading, 1978.

12. J.H. Kim, H. Kim, D. Kim, S.G. Yoon, W.K. Choo, Optical and magnetic properties of laser deposited Co-doped $\mathrm{ZnO}$ thin films // Solid State Communs. 131, p. 677-680 (2004).

13. K.J. Kim, Y.R. Park, Spectroscopic ellipsometry study of optical transitions in alloys // Appl. Phys. Lett. 81(8), p. 1420-1422 (2002).

14. K.T.R. Reddy, V. Supriya, Y. Murata, M. Sugiyama, Effect of Co-doping on the properties of $\mathrm{Zn}_{1-x} \mathrm{Co}_{\mathrm{x}} \mathrm{O}$ films deposited by spray pyrolysis // Surface and Coating Technology, 231, p. 149-152 (2013).

15. M. Subramanian, M. Tanemura, T. Hihara, V. Ganesan, T. Soga, T. Jimbo, Magnetic anisotropy in nanocrystalline Co-doped $\mathrm{ZnO}$ thin films // Chem. Phys. Lett. 487, p. 97-100 (2010).

16. S. Colis, H. Bieber, S. Begin-Colin, G. Schmerber, C. Leuvrey, A. Dinia, Magnetic properties of Codoped $\mathrm{ZnO}$ diluted magnetic semiconductors prepared by low-temperature mechanosynthesis // Chem. Phys. Lett. 422, p. 529-533 (2006).

17. A. Fouchet, W. Prellier, L. Mechin, Growth and characterizations of $\mathrm{ZnO}$ and Co-doped $\mathrm{ZnO}$ films for their use in spintronics // Superlatt. Microstruct. 42, p. 185-190 (2007).

18. N. Bahadur, A.K. Srivastava, S. Kumar, M. Deepa, D. Nag, Influence of cobalt doping on the crystalline structure, optical and mechanical properties of $\mathrm{ZnO}$ thin films // Thin Solid Films, 518, p. 5257-5264 (2010).

19. L. Wei, Z. Li, W.F. Zhang, Influence of Co doping content on its valence state in $\mathrm{Zn}_{1-\mathrm{x}} \mathrm{Co}_{\mathrm{x}} \mathrm{O}(0 \leq$ $\mathrm{x} \leq 0.15)$ thin films // Appl. Surf. Sci. 255, p. $4992-$ 4995 (2009).

20. J.K. Furdyna, Diluted magnetic semiconductors // J. Appl. Phys. 64(4), p. R29 (1988).

21. Y.G. Wang, S.P. Lau, H. Lee, S.F. Yu, B.K. Tay, X.H. Zhang, and H.H. Hng, Photoluminescence study of $\mathrm{ZnO}$ films prepared by thermal oxidation of Zn metallic films in air // J. Appl. Phys. 94, p. 354-358 (2003).

22. B. Panigrahy, M. Aslam, and D. Bahadur, Aqueous synthesis of Mn-and Co-doped $\mathrm{ZnO}$ nanorods // J. Phys. Chem. C, 114, p. 11758-11763 (2010).

23. S. Kumar, S. Basu, B. Rana, A. Barman, S. Chatterjee, Jha, and A.K. Ghosh, Structural, optical and magnetic properties of sol-gel derived $\mathrm{ZnO}$ : Co diluted magnetic semiconductor nanocrystals: an EXAFS study // J. Mater. Chem. C, 2(3), p. 481495 (2014).

24. L.J. Zhuge, X.M. Wu, Z.F. Wu, X.M. Yang, X.M. Chen, Q. Chen, Structure and deep ultraviolet emission of Co-doped $\mathrm{ZnO}$ films with $\mathrm{Co}_{3} \mathrm{O}_{4}$ nanoclusters // Mat. Chem. Phys. 120, p. 480-483 (2010).

25. F. Xu, Z.Y. Yuan, G.H. Du, M. Halasa, and B.L. $\mathrm{Su}$, High-yield synthesis of single-crystalline $\mathrm{ZnO}$ hexagonal nanoplates and accounts of their optical and photocatalytic properties // Appl. Phys. A, 86(2), p. 181-185 (2007).

26. V. Gokulakrishnan, S. Parthiban, K. Jeganathan, and K. Ramamurthi, Investigation on the effect of $\mathrm{Zr}$ doping in $\mathrm{ZnO}$ thin films by spray pyrolysis // Appl. Surf. Sci. 257(21), p. 9068-9072 (2011).

27. R. Elilarassi, G. Chandrasekaran, Influence of Codoping on the structural, optical and magnetic properties of $\mathrm{ZnO}$ nanoparticles synthesized using auto-combustion method // J. Mater. Sci.: Mater. Electron. 24, p. 96-105 (2013).

28. H. Zeng, G. Duan, Y. Li, S. Yang, X. Xu, and W. Cai, Blue luminescence of $\mathrm{ZnO}$ nanoparticles based on non-equilibrium processes: Defect origins and emission controls // Adv. Functional Materials, 20(4), p. 561-572 (2010).

29. F.L. Xian, L.H. Xu, X.X. Wang, and X.Y. Li, Crystallographic, optical and magnetic properties of Co-doped $\mathrm{ZnO}$ thin films synthesized by sol gel route // Cryst. Res. Technol. 47(4), p. 423-428 (2012).

30. S. Chakraborty, and P. Kumbhakar, Observation of bandgap narrowing effect and photoluminescence emission characteristics of chemically synthesized Co doped $\mathrm{ZnO}$ nanosheets // Indian J. Phys. 88.3, p. 251-257 (2014).

31. J. Ding, X. Yana, Q. Xue, Study on field emission and photoluminescence properties of $\mathrm{ZnO}$ /grapheme hybrids grown on $\mathrm{Si}$ substrates // Mater. Chem. Phys. 133, p. 405-409 (2012). 